\title{
Research
}

\section{Resilience among doctors who work in challenging areas:}

\author{
a qualitative study
}

\begin{abstract}
Background

Although physician burnout has received considerable attention, there is little research of doctors who thrive while working in challenging conditions.

\section{Aim}

To describe attitudes to work and job satisfaction among Australian primary care practitioners who have worked for more than 5 years in areas of social disadvantage.

Method

Semi-structured interviews were conducted with 15 primary health care practitioners working in Aboriginal health, prisons, drug and alcohol medicine, or youth and refugee health. The interviews explored attitudes towards work and professional satisfaction, and strategies to promote resilience.
\end{abstract}

\section{Results}

All doctors were motivated by the belief that helping a disadvantaged population is the 'right thing' to do. They were sustained by a deep appreciation and respect for the population they served, an intellectual engagement with the work itself, and the ability to control their own working hours loften by working part-time in the field of interest). In their clinical work, they recognised and celebrated small gains and were not overwhelmed by the larger context of social disadvantage.

\section{Conclusion}

If organisations want to increase the numbers of medical staff or increase the work commitment of staff in areas of social disadvantage, they should consider supporting doctors to work part-time, allowing experienced doctors to mentor them to model these patientappreciative approaches, and reinforcing, for novice doctors, the personal and intellectual pleasures of working in these fields.

\section{Keywords}

burnout, professional; practitioner satisfaction primary care; resilience, psychological; social disadvantage; vulnerable populations; work satisfaction.

\section{INTRODUCTION}

According to the inverse care law, ${ }^{1}$ the availability of good medical care varies inversely with the need for it in a population. ${ }^{2,3}$ The reasons why poor and disadvantaged people receive worse care than their richer and healthier compatriots are complex, 4,5 but supply-side factors play a part.,6

Discrete-time survival analysis of physicians working in community and migrant health services in the United States (US) found that the mean period of tenure of primary care physicians working in these areas was only 3 years. ${ }^{7}$ Working with disadvantaged and marginalised patients can pose challenges for physicians, whose roles often expand to include advocacy and coordination of complex patient journeys through the health system. ${ }^{2,8}$ When these roles are shoehorned into busy general practices, GPs report feeling overwhelmed. 9,10

Both work intensity and volume are cited as causative factors for physician burnout and workforce turnover.11,12 However, there is little research into the experiences of health practitioners who deliver health care to disadvantaged populations, where work intensity and volume would be expected to be high. Such research might throw light on the ways that these physicians negotiate, or mitigate, burnout.

There is some evidence that doctors who work in high-needs populations are not

AD Stevenson, DCH, FRACGP, lecturer CB Phillips, MA, MPH, DipEd, FRACGP, associate professor in social foundations of medicine, Academic Unit of General Practice and Community Health Australian National University, Canberra, Australia. KJ Anderson, MTh, FRACGP, Director of Medical Education, SENSW\&ACT LTG, CoastCityCountry Training and senior lecturer. School of General Practice, Rural and Indigenous Health, Australian National University, Canberra, Australia.

\section{Address for correspondence}

Alexander D Stevenson, Academic Unit of General necessarily overwhelmed by their work. In the US, a large quantitative study on physician turnover found that physicians with the highest proportion of uninsured patients had the lowest rates of turnover. ${ }^{13}$ In the UK, no relationship was found between deprivation and GP wellbeing. ${ }^{14}$ Doctors working in the inner parts of London reported higher rates of satisfaction than the national average. ${ }^{15}$ It is possible that long-term workers in areas of disadvantage may be sustained by organisational factors that mitigate work intensity and volume. Alternatively, practitioners may have personal characteristics that enable them to cope with stress associated with high patient needs.

The aim of this study was to explore job satisfaction and resilience among primary care doctors who have worked for sustained periods in medically underserved populations in Australia.

\section{METHOD}

This qualitative study held in-depth interviews with primary care practitioners working for 5 years or more with a medically underserved or disadvantaged population. Critical case sampling was used: a method of purposively sampling a small number of participants selected for their capacity to throw the most light on the phenomenon of interest. This method enables inductive
Practice and Community Health, Australian National University, Building 4 Level 2, The Canberra Hospital, Garran ACT 2602, Australia. E-mail: alexander.stevensondanu.edu.au Submitted: 24 October 2010; Editor's response: 19 November 2010; final acceptance: 11 January 2011.

\section{OBritish Journal of General Practice}

This is the full-length article lpublished online 27 Jun 2011) of an abridged version published in print. Cite this article as: Br J Gen Pract 2011; DOI: 10.3399/bjgp11X583182. 


\section{How this fits in}

Poor and socially disadvantaged populations receive worse care than the richer and healthier sections of the community. Doctors servicing these populations can be overwhelmed by the challenges associated with this work, which have been cited as causes of burnout and high workforce turnover. Doctors who sustain their practice in these areas describe an intellectual engagement with the work and strategies that prevent them being overwhelmed by the challenges. These new findings provide a framework for sustainable planning for the medical workforce in areas of social disadvantage.

generalisations to be made from rich data. ${ }^{16}$

The sampling frame included doctors working for 5 years or more with refugees, indigenous Australians, prisoners, disadvantaged youth, or substancedependent persons. There is a great deal of organisational diversity in primary care services in Australia, and funding for GP services is provided through two models: fee-for-service for GPs in private general practices lwhich is underpinned by Medicare, the national health insurance system) or direct salaries for doctors working in state-funded services or nongovernment organisations (NGOs). The study sampled doctors from each of these organisational models.

To explore the influence of organisational factors, the sample included GPs who worked in population-specific services (for example, a youth health servicel and in mainstream general practices where one or more of these groups formed over half the GPs' patient population.

Potential participants were initially identified within the jurisdiction in which the researchers lived, where doctors who met the inclusion criteria were interviewed. These doctors then nominated other workers in other states, who were approached for interview. Doctors in this sample include practitioners in three Australian states and one territory.

\section{Data collection}

Semi-structured interviews were conducted in person or by telephone. Questions addressed motivations for commencing and staying in this field of practice, personal attitudes to the field of practice, and organisational attributes of the service itself. All interviews were recorded and transcribed.

\section{Data analysis}

Transcripts were independently analysed by two researchers, using grounded theory, with the third researcher assessing the salience of the emerging categories. The first round of categories that emerged consisted of drivers, attitudes, and pragmatic coping strategies. A second round of analysis produced the following categories: personal meaning of work, locus of control and choice-making, routes into the field of practice, and the influence of organisation on commitment to work. The emergent theory was that reflectiveness, respectful engagement with the job, and a clear sense of boundaries and limits were important in mitigating the impact of work volume and intensity, which organisations often struggled to contain.

\section{Table 1. Demographic details of participants}

\begin{tabular}{lcccc} 
Participant number & Sex & $\begin{array}{c}\text { Age range, } \\
\text { years }\end{array}$ & $\begin{array}{c}\text { Years since } \\
\text { graduation }\end{array}$ & $\begin{array}{c}\text { Years working } \\
\text { in area }\end{array}$ \\
\hline 1 & $M$ & $30-39$ & 14 & 7 \\
\hline 2 & $F$ & $50-59$ & 29 & 12 \\
\hline 3 & $M$ & $40-49$ & 19 & 7 \\
\hline 5 & $M$ & $50-59$ & 32 & 7 \\
\hline 6 & $F$ & $40-49$ & 24 & 13 \\
\hline 7 & $M$ & $40-49$ & 24 & 20 \\
\hline 8 & $M$ & $50-59$ & 25 & 12 \\
\hline 9 & $M$ & $50-59$ & 31 & 5 \\
\hline 10 & $F$ & $50-59$ & 26 & 6 \\
\hline 11 & M & $30-39$ & 11 & 13 \\
\hline 13 & $F$ & $50-59$ & 30 & 12 \\
\hline 14 & $M$ & $50-59$ & 25 & 16 \\
\hline 15 & $M$ & $50-59$ & 31 & 31 \\
\hline
\end{tabular}




\section{Box 1. Entering the field}

'I think it was a sense of social justice more than anything. My intention in doing [medicine] was ... to make a difference and it became apparent to me from very early on in the medical course that where there was most need to make a difference was in Aboriginal health.' (\#14)

' am in a helping profession and there are people [in] need ... it is a disadvantaged population and this is something that I can do.' (\#5)

.. I think that social justice stuff is worthwhile and interesting.' (\#12)

'A bit of it was just serendipity, because I met this girl who was just so enthusiastic and she was young and she just, sort of, dragged me in right from the word go.' (\#2)

'When I came back to Canberra, the opportunity came up, but I really was, as I said, just a fill in initially. But, that's the way career paths go, I suppose.' (\#7)

\section{Box 3. Locus of control}

I have chosen public practice because I had choice... Sure, I could have equally gone into private practice and striven for the yacht and that [but] ... it doesn't fit comfortably with me. But I can jump out of bed every morning; look forward to the new day ... I still aspire to achieve something every day professionally or through advocacy.' (\#8)

'Well, I had the choice to work with [a refugee health service] and I absolutely, specifically went there and I went there because I felt comfortable, because I knew I'd done that work before in my general practice training. (\#9)

I've been able to realise that I love clinical general practice, but I've begun to realise that there are real benefits in doing some other things and I think there are benefits in doing other work-related things.' (\#13)

\section{RESULTS}

Demographic details of the sample are presented in Table 1.

There were nine males and six females; the modal age was in the 50-59 years age group. Fourteen had trained as GPs, and one had trained in internal medicine. Median length of time from graduation was 25.5 years, and the mean length of time working in their area of social disadvantage of 10.1 years. Mean proportion of all working years spent working in the area of social disadvantage was 42\% (range = 19 to $80 \%$ ).

Six doctors worked in indigenous health, four worked with refugees, three worked in prison health, one worked with substancedependent persons, and one worked with disadvantaged youths. Only one participant worked full-time in the disadvantaged area. Most participants had structured their working week so that they could combine clinical work in the area with mainstream general practice the rest of the time (nine doctors), academic work (three doctors), and one each in healthcare administration and non-medical work.

\section{Entering the field}

The motivation for working in areas of disadvantage for most doctors was the belief that helping a disadvantaged population was the 'right thing' to do. Some people had an affinity for working with a particular group and strove to find work in that area. For others, wanting to make a difference combined with a serendipitous job opportunity led them to their workplace (Box 1). Although religion formed part of the personal frame of reference for seven responders, only two described their decision to work in this area as being driven by religion.

\section{Personal meaning of work}

All doctors reported finding meaning and satisfaction in their work. While they were aware of the potential for burnout and the need to manage their workload, they described the work itself with delight. When asked about the widespread opinion that the populations they worked with had a high proportion of 'heartsink' patients, they vehemently disagreed. A common response was to appropriate and subvert the term, using the feeling of 'heartsink' as a motivator to do more for the patient (Box 2).

\section{Locus of control}

Participants tended to see themselves as being in control of their working lives on two levels: personal and in the patient-doctor

\section{Box 2. Personal meaning of work}

Most GPs that work in Aboriginal health think its fun. It's a hoot sometimes. Partly because you've got people to debrief with and share the responsibility with, but it's, I don't know, it's just the clients seem to be always in desperation, but they've got a wicked sense of humour.' (\#12)

I enjoy other cultures and I enjoy consulting in another language with people from different areas that are totally different point of view to and culture to people like me I guess. I find that interesting. (\#1)

'I'm inspired by most of my patients.' (\#13)

I suppose I've actually had some of my best experiences with my 'heartsink' patients that other people would label like that ... As soon as I start labelling them as heartsink', I actually decide that there's more that I can do because I'm missing something; and I have yet to be disappointed with that approach.' (\#9)

'There are patients that you see that you think, "Oh dear, it's so-and-so again" and you say to yourself, that this is a person who's got rights, who is doing their best to live their life by their own values, their own circumstances, and you start to see the good in them, you start to see their achievements, their essential humanity. (\#13)

'I don't see it as altruistic. I mean, life and human relationships and how we get on with each other and how systems and communities work is a fascination for me ... I think altruism is, if such a thing exists, is built into all of us, to one degree or another; we just have a different capacity and perception of how our long- and medium-term interests are served by considering other people's needs at the same time as ours.' (\#4).

relationship. On a personal level, they articulated a sense of control, or decision making, about where they worked and how they worked; for example, by compartmentalising their working week (Box 3). At the level of the patient-doctor interaction, doctors stated that they are not solely responsible for healthcare outcomes. At the same time, they did not blame patients for not improving their own health. Thus the doctors' notion of control at the micro-level was subtle and calibrated to recognise, but not be overwhelmed by, the scale of disadvantage faced by their patients. These doctors were able to establish markers of success that reflected what they could and did achieve, even when these were small (Box 4).

Two doctors had taken time out from their 


\section{Box 4. Pragmatic markers of success}

I think if you keep a view of that control lying with the patient and that you re working with the patient but ultimately the decision making and the control is with the patient. Then it's, it's somewhat easier to accept situations that seem from your perspective as a doctor to be less than ideal.' (\#14)

Substance abuse is always a difficult area, 'cause you don't get many cures. But, if you get someone onto methadone and give them out of gaol, that might be a success. If you keep someone alive for 5 years longer than they would have otherwise, you get to judge that as a success as well.' (\#7) work in disadvantaged areas when they recognised that they were close to burning out. Others discussed changing their lives to ensure that they had resources outside of their work to enable them to remain enthusiastic about their jobs. For many, this involved working part time in the area.

\section{Organisational support}

The structure or functionality of the organisation was rarely cited as a determinant of sustained practice. That this cohort rarely worked full-time in these organisations may have distanced them from organisational stress. If they did comment on the failures of the organisations, it was with the kind of pragmatism they brought to individual patient challenges. Several doctors commented that to work in these areas one had to be able to work as a member of a team (Box 5).

\section{DISCUSSION}

\section{Summary}

This is the first study to undertake in-depth interviews on resilience and work enjoyment with a sample of doctors who have worked for sustained periods in socially-marginalised communities. In his formulation of the inverse care law, Hart noted that its impacts were felt most strongly where market forces predominated.' This study was undertaken in Australia, which has a national health insurance system and state-funded services. For most of the population served in the urban services of this study, demandside factors (cost or availability) that influence the inverse care law are minimised.

Supply-side problems do exist in Australia. Indigenous health services have difficulty attracting and retaining GPs, ${ }^{17}$ and patient:doctor ratios in Australian prison health services ${ }^{18}$ are higher than those reported in Irish $^{19}$ and UK prisons. ${ }^{20}$ Because Australia has a pluralistic primary care system, with both for-profit private general practice (increasingly corporatised), and not-for-profit state and community services, the study results have relevance both for countries with national health insurance systems like ours (for example the UK, Canada, and New Zealandl and for those based on fee-for-service or corporatised systems, such as the US.

\section{Strengths and limitations}

This study was a critical case sample of 15 doctors. Although this was a small sample, saturation was achieved in that themes were being repeated across the sample of doctors. The doctors worked in a broad range of areas but all were in an urban location. This does not represent an intentional geographical bias, but instead reflects that services for these patient populations are often located in urban settings. The study would have benefited from exploring the perspectives of those working in more remote areas, where it may be more difficult to create the portfolio careers of the doctors in this study.

\section{Comparison with existing literature}

This study provides the perspective of doctors themselves on long-term work in disadvantaged urban communities. All doctors were aware of the potential for burnout; some had experienced it and removed themselves temporarily from the field. However, overall, these doctors thrived in their work.

Many of these doctors described their motivation as 'to do good' or 'make a difference'. There is a body of literature that argues the finer points of altruism and concepts of obligation, fiduciary responsibility, and sacrifice. ${ }^{21-23}$ The doctors in this study actively distanced themselves from the notions of selfless service and sacrifice implicit in most discussions of altruism in practice. ${ }^{24} \mathrm{It}$ may be more useful to understand their approach to their work and its sustainability using the notion of prosociality.

'Prosociality', like altruism, is a social psychology construct that refers to behaviours of giving, helping, and creating harmonious relationships. Unlike altruism, which is driven by unobservable inner motivations, prosociality is defined largely through behaviour rather than motivation. Focusing on prosociality, from a research point of view, enables us to move from a focus on individual moral drivers to observable behaviours and the contexts in which people are most supported to act in prosocial ways

What is the connection between prosociality and resilience? Preliminary work suggests that some doctors may experience 'vicarious resilience' through working with traumatised patients who embody everyday survival. ${ }^{25}$ The literature on vicarious resilience is poorly developed and, like the more extensive literature on vicarious traumatisation, is hampered by the absence of a robust research base. ${ }^{26}$ However, determinants of vicarious traumatisation appear to be multifactorial , and include both attitudinal and contextual matters. ${ }^{27}$ The same is probably true of 
vicarious resilience. In the present study, there appear to be three behaviours described by doctors that enabled them to derive strength and resilience from working with marginalised groups: respect for their patients; maintaining a sense of control; and having an interest in their work.

Respect for patients. The doctors were united in their appreciation and respect for their patients, recounting a sense of privilege in being able to work with and be trusted by a marginalised community. Although many acknowledged that large improvements in health outcomes were often difficult to achieve, they were willing to accept and applaud small or incremental changes. In their overview, Mead and Bowers noted that patient-centred practice comprised five conceptual dimensions: biopsychosocial, patient-as-person, doctoras-person, therapeutic alliance, and sharing power and responsibility. ${ }^{28}$ While all these dimensions are apparent in the approaches of the doctors in the present study, the strongest was the patient-asperson. The narratives or cultural backstories of individual patients - their 'biographies'29 - were evident in the doctors' accounts of adjusting to, understanding, and responding to each patient's context and needs.

A sense of control. The doctors expressed that they had a sense of control over their practice. Locus of control is a personality trait, with those with an internal locus of control tending to be happier and healthier in their endeavours. ${ }^{30}$ Doctors tend to have internal loci of control, and when this is violated - for example, through being unable to control their working life - this tends to be translated into frustration and a desire to leave the field. ${ }^{31}$ The doctors in the present survey repeatedly described choice making in their careers. They capitalised on serendipitous opportunities to enter the field and they frequently put boundaries around their work. For example, most did not work full-time in the field but instead worked in portfolio careers including different clinical fields, advocacy, and teaching. Participants described this boundary setting as a way of retaining control over their working lives rather than as a reaction to the difficulties of the workplace itself.

Attempts to increase services to the uninsured and underinsured in the US have found that volunteering part-time was thought to be feasible by doctors, when fulltime work was not. ${ }^{32}$ Doctors in the US
National Health Service Corps - which places student loan recipients in approved services for the poor or marginalised after graduation - are more likely to stay beyond their 2-year tour of duty if they have higher salaries and greater job satisfaction. ${ }^{33}$ In the present study, the relatively low levels of reimbursement for working in the field was rarely mentioned as a barrier by participants; however, this population with their varied careers could afford to carry low-paid work, as it was offset by other work. However, it is unknown whether low levels of reimbursement would undermine the internal locus of control for doctors working full-time in the field.

Although, in theory, organisational culture would be expected to impact on physician burnout, there is little empirical evidence to support this. ${ }^{34}$ In the present study, organisational factors did not seem to play a part in the resilience of doctors, nor did they necessarily reinforce locus of control. A number of doctors worked in organisations that were described (with sympathyl as 'driven' and 'somewhat chaotic'. Many organisations had actively mentored doctors when they were less experienced. Overall, at this stage in their careers, doctors had often worked longer in the organisation than the managers and were able to separate organisational issues from the clinical issues that they were dealing with. The ability to work as a part of a team of health professionals tended to be cited as a resilience strategy that reinforced internal locus of control, perhaps because it allowed doctors to initiate sharing the burden of some complex patients.

Intellectual interest. These doctors are intellectually interested in their work, and described reflecting deeply on it. A study of community nurses who had sustained their practice in areas of disadvantage found that characteristics such as reflectiveness and job engagement enabled them to thrive in this work. ${ }^{35}$ The present results suggest that intellectual engagement was one of the tools that underpinned doctors' internal locus of control, as it often helped practitioners to find new perspectives on their patients and the social situations that kept them marginalised and poor.

\section{Implications for practice}

These doctors exhibit prosocial behaviour and are models of 'the good work' that can be done in medicine particularly in terms of patient-centred care. Bishop and Rees argue that this form of sustainable prosocial behaviour is an important model that
Contribute and read comments about http://www.rcgp.org.uk/bjgp-discuss 
should be taught in medical schools. ${ }^{24}$ Doctors who are experienced in providing prosocial patient care are well placed to be role models and teachers to students. Some of the doctors interviewed hold academic positions and others are involved in teaching at both undergraduate and postgraduate levels. By having students and junior doctors with them in the clinic, they can teach, by example, actions that benefit the most disadvantaged members of society, while at the same time achieving balance and caring for the self.
This study has implications for efforts to increase the medical workforce for socially marginalised patient populations. The way doctors organise their work appears to protect them from work-associated distress, as does their intellectual engagement and reflective empathy with patients. Efforts to increase the workforce should rest on supporting other doctors to learn about the sustaining strategies and pleasures of working part time with marginalised patient populations. 


\section{REFERENCES}

1. Hart JT. The inverse care law. Lancet 1971; 1(7696): 405-412

2. Mercer SW, Watt GCM. The inverse care law: clinical primary care encounters in deprived and affluent areas of Scotland. Ann Fam Med 2007; 5(6): 503-510.

3. Hart JT. Three decades of the inverse care law. BMJ 2000; 320(7226): 18-19.

4. Stirling AM, Wilson P, McConnachie A. Deprivation, psychological distress, and consultation length in general practice. Br J Gen Pract 2001; 51(467): 456-460.

5. Fiscella $K$, Shin P. The inverse care law: implications for healthcare of vulnerable populations. J Ambul Care Manage 2005; 28(4): 304-312.

6. Knox PL, Pacione M. Locational behaviour, place preferences and the inverse care law in the distribution of primary medical care. Geoforum 1980; 11: 43-55

7. Singer JD, Davidson SM, Graham S, Davidson HS. Physician retention in community and migrant health centers: who stays and for how long? Med Care 1998; 36(8): 1198-1213.

8. Fiscella K, Epstein RM. So much to do, so little time: care for the socially disadvantaged and the 15-minutes visit. Arch Intern Med 2008; 168(17): 1843-1852.

9. Johnson DR, Ziersch AM, Burgess T. I don't think general practice should be the front line: experiences of general practitioners working with refugees in South Australia. Aust New Zealand Health Policy 2008; 5: 20

10. Van den Hombergh P, Künzi B, Elwyn G, et al. High workload and job stress are associated with lower practice performance in general practice: an observational study in 239 general practices in the Netherlands. BMC Health Serv Res 2009; 9: 118

11. Malach $C$, Jackson SE. The measurement of experienced burnout. J Organ Behav 1981; 2: 99-113

12. Rafferty JS, Lemkau JP, Purdy RR, Rudisill JR. Validity of the Maslach burnout inventory for family practice physicians. J Clin Psychol 1986; 42(3): 488-492.

13. Williams ES, Konrad TR, Linzer Mark, et al. Physician, practice, and patient characteristics related to primary care physician physical and mental health: results from the physician worklife study. Health Serv Res 2002; 37(1): 119-141.

14. Grieve S. Measuring morale - does practice area deprivation affect doctors well-being? Br J Gen Pract 1997; 47(422): 547-552.

15. Sibbald B, Bojke C, Gravelle H. National survey of job satisfaction and retirement intentions among general practitioners in England. BMJ 2003; 326(7379): 22.

16. Patton MQ. Qualitative research and evaluation methods. 3rd edn. Thousand Oaks CA: Sage, 2002.
17. Bailie R, Si D, Dowden M, et al. Improving organisational systems for diabetes care in Australian Indigenous communities. BMC Health Serv Res 2007, 7: 67

18. Australian Institute of Health and Welfare. The health of Australia's prisoners 2009. Cat no PHE 123. Canberra: Australian Institute of Health and Welfare, 2010.

19. Barry JM, Darker CE, Thomas DE, et al. Primary medical care in Irish prisons. BMC Health Serv Res 2010; 10: 74.

20. HM Chief Inspector of Prisons. Annual report of Chief Inspector of Prisons 2005/6. London: Home Office, 2007.

21. Downie, R. Supererogation and altruism: a comment. J Med Ethics 2002; 28(2): $75-76$.

22. Glannon W, Ross LF. Are doctors altruistic? J Med Ethics 2002; 28(2): 68-69.

23. McKay A. Supererogation and the profession of medicine. J Med Ethics 2002; 28(2): 70-73.

24. Bishop J, Rees C. Hero or has-been: is there a future for altruism in medical education? Adv Health Sci Educ Theory Pract 2007; 12(3): 391-399.

25. Hernandez $P$, Gangsei D, Engstrom D. Vicarious resilience: a new concept in work with those who survive trauma. Fam Process 2007; 46(2): 229-241.

26. Dunkley J, Whelan TA. Vicarious traumatisation: current status and future directions. Br J Guid Couns 2006; 34: 107-116.

27. Lerias D, Byrne MK. Vicarious traumatisation: symptoms and predictors. Stress Health 2003; 19(3): 129-138

28. Mead N, Bowers P. Patient-centredness: a conceptual framework and review of the empirical literature. Soc Sci Med 2000; 51(7): 1087-1110.

29. Armstrong, D. The emancipation of biographical medicine. Soc Sci Med 1979; 13A(1): 1-8.

30. Danna K, Griffin R. Health and well-being in the workplace: a review and synthesis of the literature. J Manage 1999; 25(3): 357-384.

31. Spickard Jnr A, Gabbe SG, Christensen JF. Midcareer burnout in specialist and generalist physicians. JAMA 2002; 288(12): 1447-1450.

32. Scott HD, Bell H, Geller S, Thomas M. Physicians helping the underserved: the Reach Out program. JAMA 2000; 283(1): 99-104.

33. Porterfield DS, Konrad TR, Porter CQ, et al. Caring for the underserved: current practice of alumni of the National Health Service Corps. $J$ Health Care Poor Underserved 2003; 14(2): 256-271.

34. Williams ES, Manwell MB, Konrad TR, Linzer M. The relationship of organizational culture, stress, satisfaction, and burnout with physicianreported error and suboptimal patient care: results from the MEMO study. Health Care Manage Rev 2007; 32(3): 203-212.

35. Vinje HF, Mittelmark MB. Community nurses who thrive: the critical role of job engagement in the face of adversity. J Nurses Staff Dev 2008; 24(5): 195-202. 